\title{
LA CONSOLIDACIÓN DE UNA NUEVA ESTRATEGIA EN LAS RELACIONES ENTRE LA CORONA DE ARAGÓN Y EL MAGREB HAFSÍDA: EL TRATADO DE 1403 Y SUS PERSPECTIVAS MERCANTILES
}

\author{
THE CONSOLIDATION OF A NEW STRATEGY \\ IN THE RELATIONSHIP BETWEEN THE CROWN OF ARAGON \\ AND HAFSID MAGHREB: \\ THE AGREEMENT OF 1403 AND ITS MERCANTILE PROSPECTS
}

\author{
M a DOLORES LÓPEZ PÉREZ \\ J.IGNACIO PADILLA LAPUENTE \\ Universidad de Barcelona
}

\begin{abstract}
Resumen: La coyuntura política del reino de Túnez repercutió de forma decisiva sobre las aspiraciones y fracasos de sus relaciones diplomáticas y comerciales con las potencias europeas. Tras un periodo prolongado jalonado por acuerdos sucesivos, las viejas pretensiones tributarias de la Corona de Aragón alcanzarán a ser reconocidas en el tratado suscrito en 1360 , aunque aquel acuerdo no conseguirá hacer efectiva en la práctica dicha reclamación. El fortalecimiento del poder de los Hafsíes en las últimas décadas del siglo XIV reabre un periodo de confrontación velada con la intensificación de las actividades corsarias, que culminan en sendas expediciones de castigo sobre puertos magrebíes. El tratado de 1403 pondrá fin a dichas hostilidades y reabrirá una nueva estrategia en las relaciones con el Magreb Hafsída.

Palabras clave: Magreb; Tratados de paz; Hafsíes; Comercio mediterráneo; Cautivos.
\end{abstract}

\begin{abstract}
The political situation in the Kingdom of Tunis had a decisive influence on the targets and failures of its diplomatic and commercial links with the European powers. After a long period marked by successive agreements, the old objectives of the Crown of Aragon concerning the tax system were to be recognized in the agreement achieved in 1360, although that agreement is not achieved in practice enforce that claim. The strengthening of the Hafsid authority during the last decades of $14^{\text {th }}$ Century opened a period of veiled confrontation. The increasing of the pirate actions, which culminated with the punishment expeditions on seaports of Maghreb, were an evidence for this confrontation. The agreement of 1403 ended up the hostilities and opened a new political strategy within the relationship between Crown of Aragon and Hafsid Maghreb.

Key words: Maghreb; Peace treaties; Hafsíes; Mediterranean trade; Captive.
\end{abstract}

\section{SUMARIO}

1. Introducción.- 2. Los antecedentes: el tratado de 1360.- 3. De 1370 a 1403: El cambio de coyuntura.- 4. La firma de la paz: El acuerdo de 1403.- 5. Conclusiones. 


\section{INTRODUCCIÓN}

A principios de 1403 se reunían los embajadores del sultán hafsí, Abu Faris, y del monarca de la Corona de Aragón, Martín I, con el objetivo de llegar a un acuerdo que posibilitase la apertura de un período de paz y favoreciese un estrechamiento de las relaciones políticas y, sobre todo, económicas, entre los dos territorios. La coyuntura no podía ser más adversa. El considerable incremento de la piratería hafsí, detectado documentalmente desde la década de los 60-70, había justificado la contraofensiva cristiana materializada en una cruzada. Dos ciudades, una zayyaní, Tedelis, y otra hafsí, Bona, habían sido saqueadas pocos años antes, en 1398 y 1399, como represalia por los continuos saqueos protagonizados por los corsarios magrebíes.

En este contexto, sumamente complejo, la habilidad diplomática de los embajadores y la urgente necesidad de acordar una tregua que posibilitase, por un lado, la redención de cautivos y, por el otro, revitalizase unos intercambios sin duda afectados por el clima de guerra existente, posibilitó un entendimiento entre las partes implicadas. Finalmente, en marzo de 1403, se llegaría a un acuerdo definitivo con la firma de un tratado que tendría una vigencia de cinco años ${ }^{1}$. Hacía treinta y cuatro que la paz había dado paso a un clima de hostilidades permanentes. Ello no significaba, naturalmente, que se abriese una confrontación entre ambos estados pero sí que quedaba legalizada la guerra de corso. Durante treinta y cuatro años los corsarios respectivos pudieron capturar con total impunidad, y sin posibilidad de presentar reclamaciones, navíos, mercancías y súbditos, un negocio incluso más lucrativo que el propio comercio.

El último pacto conocido se había firmado cuarenta y tres años antes, en 1360. Con una duración prevista de diez años, su vigencia quedaría anulada pocos meses antes de su finalización, en febrero de 1369, al morir una de las dos partes contratantes: el hafsí Abu Ishaq. Y hasta 1403 no hay indicios de ningún otro acuerdo. Las preguntas que se plantean son numerosas: ¿Qué sucedió en ese lapso de tiempo que justifique un enrarecimiento de las relaciones, hasta el punto de convocarse una cruzada? ¿Qué soluciones se adoptaron en ese tratado? ¿En qué se vieron modificadas las relaciones entre la Corona de Aragón y Túnez? ¿Cómo afectaron estos pactos al sector mercantil? Intentaremos, a través del análisis de los contenidos del acuerdo de

${ }^{1} \mathrm{El}$ tratado de 1403 ha sido publicado por Estanislao AGUILÓ, Pau feta entre els reys de Aragó y de Sicilia de una part y el rey de Tunis de l'altre (1403), "Boletín de la Sociedad Arqueológica Luliana" (1909-1910), pp. 350-355. Encontramos asimismo numerosas referencias a este acuerdo en José M. RAmOS LOSCERTALES, El cautiverio en la Corona de Aragón durante los siglos XIII, $X I V$ y XV , Zaragoza: Publicaciones del Estudio de Filología de Aragon, 1915 pp. 31-32; Antoni IVARS, Dos creuades valenciano-mallorquines a les costes de Berberia, Valencia: Imp. Olmos y Luján, 1921, p.CXXXI; Pierre MACAIRE, Majorque et le commerce internacional (1400-1450 environ), Lille: Université de Lille, 1986, pp.400-401; Robert BRUNSCHWIG, La Berbérie orientale sous les Hafsides des origines à la fin du XVe siècle, París: Librairie d'Amérique et d'Orient, 1982 , vol.I, pp. 224-225; Jaime SASTRE, Aportación mallorquina a la Armada Santa. 1398-99,' "Bolletí de la Societat Arqueològica Lul-liana", 832-833 (1980), p. 504. 
1403 y su comparativa con el tratado de 1360 contestar algunas de estas cuestiones.

\section{LOS ANTECEDENTES: EL TRATADO DE 1360}

Tras una primera tentativa exenta de éxito ${ }^{2}$, Francesc Sacosta conseguiría llegar a un acuerdo satisfactorio reflejado en la suscripción de un tratado, con fecha del 15 de enero de 1360, para un periodo de diez años ${ }^{3}$.

La coyuntura política era favorable. Tras un período de ocupación mariní y de fuerte inestabilidad interna, el sultán hafsí, Abu Ishaq, había conseguido restablecer la soberanía en la práctica totalidad de territorios de Ifriqiya, en Túnez y Bugía. Sólo quedaba fuera de su órbita el gobierno de Constantina, en manos de Abu-l-Abbas ${ }^{4}$. La muerte del sultán mariní, Abu Inan, y los problemas sucesorios desencadenados a raíz de su fallecimiento muestran como la posibilidad de recuperación del poder hafsí se había logrado en realidad gracias a la profunda crisis política que afectaba los propios mariníes. Con independencia de las causas últimas que motivasen ese transvase de poderes la cuestión es que la recuperación del control de los territorios por parte de Abu Ishaq propició la apertura de contactos diplomáticos, aunque se llevaran a término a instancias de la Corona de Aragón. El resultado ya es conocido: la firma del tratado de 1360.

Las cláusulas del acuerdo incluyen idénticas especificaciones a las registradas en tratados anteriores referentes a cuestiones de regulación de la piratería, infraestructura comercial e impuestos de importación-exportación

\footnotetext{
${ }^{2}$ Nos referimos a la embajada dirigida por Arnau de Térmens: Andrés GIMÉNEZ SOLER, Documentos de Túnez originales o traducidos del Archivo de la Corona de Aragón, "Anuari de l'Institut d'Estudis Catalans", (1909-1910), doc.22, pp. 256-257; R. BRUNSCHWIG, La Berbérie orientale, I, p.181; Josefina MUTGÉ, Algunas noticias sobre las relaciones entre la corona catalana-aragonesa y el reino de Túnez de 1345 a 1360, en "Relaciones de la Península Ibérica con el Magreb (siglos XIII-XVI)", Madrid: Consejo Superior de Investigaciones Científicas, Instituto Hispano-Arabe de Cultura, 1988, p. 142.

${ }^{3}$ Isidro DE LAS CAGIGAS, Un traité de paix entre le roi Pierre IV d'Aragon et le sultan de Tunis Abu Ishak II (1360), "Hesperis", XIX (1934), pp. 65-77; Maximiliano ALARCÓN, Ramón GARCÍA DE LINARES, Los documentos árabes diplomáticos del Archivo de la Corona de Aragón, Madrid: Imp. Estanislao Maestre, 1940, doc.140 bis, pp. 311-320. Un estudio sobre este tratado puede verse en J. MUTGÉ, Algunas noticias, pp.142-144. Véase también a este respecto A. GIMÉNEZ SOLER, Documentos de Túnez, docs.XXXI-XXXII, pp.254-257; Charles-E DUFOURCQ Les activités politiques et économiques des catalans en Tunisie et en Algerie Oriental de 1262 à 1377, "Boletín de la Real Academia de Buenas Letras" XIX (1946), pp 84-85. Zurita registra este tratado pero lo data erróneamente en torno a 1355 [Anales de la Corona de Aragón, Zaragoza: Consejo Superior de Investigaciones Científicas, 1973, vol.4, p. 265].

${ }^{4}$ Dominique Valérian remarca, muy acertadamente, el anacronismo que supone hablar de territọrio o frontera en referencia al Magreb medieval, por varios motivos, pero muy especialmente por el sentimiento de pertenencia a la comunidad musulmana que prohíbe pensar en fronteras internas en el mundo islámico, las únicas legítimas son las que separan del mundo cristiano. Lo que sucede es que la realidad política contradice esos principios y los poderes regionales se constituyen, ya desde la época abassí, ejerciendo su autoridad sobre un espacio determinado. Los mismos geógrafos, afirma Valérian, muestran la emergencia de una diferenciación territorial y una representación mental del espacio político. El territorio sería, por tanto, la expresión de la afirmación de un estado a partir de su capital [Dominique VALÉRIAN, Frontières et territoire dans le Maghreb de la fin du Moyen Age: les marches occidentales du sultanat hafside, "Correspondances" no73 (novembre 2002-fevrier 2003), pp. 3-4; edición electrónica: www.irmcmaghreb.org/IMG/pdf/correspondances_73.pdf].
} 
de mercancías. Hasta aquí nada nuevo. No obstante, la principal novedad de este tratado es la consecución final del reconocimiento del pago de un tributo anual por parte del sultán hafsí al monarca catalano-aragonés ${ }^{5}$.

¿Por qué acepta el sultán esta 'compra de la paz'? Abu Ishaq gobernaba un territorio libre del peligro mariní, pero enormemente desmembrado en su interior. Su gobierno efectivo en determinados enclaves se veía interferido por los intentos de antiguos emires de recuperar sus dominios. El emir de Bugía depuesto por Abu Inan en 1352, Abu Abd Allah, no cesaba en sus ataques con el objeto de reconquistar la ciudad, lo que consiguió finalmente en 1364, apoderándose pocos meses después de Tedelis. Bona había sido ocupada, ya en 1360, en nombre del emir de Constantina, Abu-1Abbas, por uno de sus hermanos, Abu Yahya Zakariya. Además, no podía tener la certeza de que las pretensiones de Abu-l-Abbas no estuvieran dirigidas a hacerse con el control de la capital, Túnez ${ }^{6}$.

Esta coyuntura interna explicaría, por un lado, que el tratado al ser nominal sólo tuviera vigencia en un parte del territorio hafsí; Mientras que, por otro, justificaría la relativa sumisión mostrada por Abu Ishaq en el momento de aceptar el pago de un tributo. Es probable que el sultán pretendiera con dicha maniobra gozar de una situación privilegiada respecto a la Corona de Aragón de cara a sus oponentes, especialmente en el caso hipotético de necesitar una ayuda militar, naval o terrestre.

Por otro lado, la ocupación de Tremecén y de gran parte del territorio zayyaní por el sultán mariní Abu Salim, retomando la política expansionista de sus antecesores Abu-l-Hasan y Abu Inan, hacía temer una nueva campaña en Ifriqiya. Este hecho parece confirmarse por una disposición anexa al tratado en la que se especificaba la posibilidad de alquilar galeras catalanoaragonesas al precio de 1.000 dinares mensuales; un precio notablemente desproporcionado.

Sin embargo, cabe advertir que la aceptación tácita de satisfacer el tributo no suponía que el pago llegara a materializarse en su totalidad. Bien al contrario, las noticias posteriores confirman las continuas reclamaciones elevadas por la corte catalanoragonesa exigiendo el pago de un tributo que nunca acaba de llegar y que constituirá durante años motivo de fricción entre las partes ${ }^{7}$.

${ }^{5}$ Durante el período de vigencia de la tregua, Pedro el Ceremonioso percibiría cada año un total de 2.000 dinares sobre los ingresos de las aduanas tunecinas. La recaudación se efectuaría en base a la retención del $50 \%$ de las cantidades abonadas por los súbditos de la Corona de Aragón, especificando que si el total anual correspondiente a este porcentaje superaba los 2.000 dinares la diferencia quedaría en poder de la aduana; por el contrario, si no se alcanzaba la cantidad especificada se compensaría con el remanente de cualquier otro año [M. ALARCÓN, R. GARCÍA DE LINARES, Los documentos árabes, doc.140 bis, pp. 311-320].

${ }^{6}$ IBN JALDỨ , Histoire des berbères et des dynasties musulmanes de l'Afrique septentrionale París : Librairie Orientaliste Paul Geuthner, 1969, vol. III, pp.66-70; R. BRUNSCHWIG, La Berbérie orientale, I, pp. 179-180.

${ }^{7}$ Un análisis detallado de las embajadas enviadas por Pedro el Ceremonioso en un intento de conseguir el pago del tributo puede verse en M. Dolores LÓPEZ PÉREZ, La Corona de Aragón y el Magreb en el siglo XIV (1331-1410), Barcelona: Institució Milà i Fontanals, 1995, pp. 150155. Puede consultarse asimismo M.Dolores López. "Política y comercio en el Mediterráneo occidental medieval: la conformación del cuadro diplomático y su repercusión en los intercambios 


\section{DE 1370 A 1403: EL CAMBIO DE COYUNTURA}

A finales de la década de los sesenta se abre una nueva etapa en las relaciones Corona de Aragón-Ifriqiya, que se ha atribuido a un cambio de orientación en la política de Pedro III respecto al Magreb oriental. Una nueva estrategia, que según Dufourcq, se caracteriza por una progresiva y marcada hostilidad que viene a sustituir los intentos de relación pacífica que refleja el envío sucesivo de embajadas ${ }^{8}$. Sin embargo, esta hostilidad creciente, como ya tendremos ocasión de examinar más adelante, estaría en gran parte condicionada por los cambios producidos en la política tunecina a partir de 1370 y, en particular, a raíz de la unificación de Ifriqiya bajo el gobierno de Abu-1-Abbas.

Desde la recuperación pacífica de Constantina en 1360, el emir Abu-1Abbas continuó con la progresiva ocupación de Bona, Bugía y Tedelis. La muerte de Abu Ishaq en 1369 y la sucesión en el trono de su hijo, Abu l-Baqa Halid, aún niño, propició los proyectos de Abu l-Abbas quien, tras un corto asedio a la ciudad de Túnez, conseguiría, en 1370, imponerse como cabeza visible de un estado hafsí reunificado ${ }^{9}$. Desde entonces, no dejaría de incorporar todos aquellos territorios perdidos por sus antecesores: el Sahel, Susa, Mahdia, Djerba ${ }^{10}$, una labor continuada por su hijo, Abu Faris, quien logró consolidar la unidad hafsí tras extirpar las dinastías locales de Trípoli, Gafsa, Tozeur y Biskra ${ }^{11}$.

La coyuntura política es diametralmente opuesta a la que se desarrollaba en esos momentos en el resto del Magreb. Mientras el Magreb occidental era objeto de una verdadera política de injerencia externa -nazarí y castellana-, y el reino de Tremecén se debatía entre la tutela alternativa de Mariníes y Hafsíes, éstos últimos conocían, en el último cuarto del siglo XIV, una notable recuperación y una restauración de la unidad del territorio, hasta entonces fraccionado e intervenido también por la tutela mariní.

La existencia de una estructura estatal paulatinamente fortalecida, capaz de controlar su territorio, debería influir necesariamente en las relaciones Corona de Aragón / Ifriqiya. Tras la reunificación bajo el único gobierno de Abu-l-Abbas de los principales centros políticos hafsíes, el sultán

económicos Magreb-Corona de Aragón (ss.XIII-XV)”, en Simonetta Cavaciocchị (ed.), Relazioni economiche tra Europa e mondo istamico secc.XIII-ẌVIII, Firenze: Le Monnier, 2007, vol.I, pp.444-446.

${ }^{8}$ Aquéllas tenían como uno de sus principales objetivos el cobro del tributo. Charles-E. DUFOURCQ, Documents inédits sur la politique ifrikiyenne de la Couronne d'Aragon, "Analecta Sacra Tarraconensia», XXV (julio-diciembre 1952), p.291.

${ }^{9}$ IBN JALDÚN, Histoire des berbères, III, pp.78-83; R. BRUNSCHWIG, La Berbérie orientale, I, pp. 185-187.

${ }^{10}$ IBN JALDÚN, Histoire des berbères, III, pp.85-123; R. BRUNSCHWIG, La Berbérie orientale, I, pp. 189-195.

${ }^{11} \mathrm{R}$. BRUNSCHWIG, La Bérbérie orientale, I, pp.210-216. Los límites orientales de Ifriqiya estarían en la época hafsí, aproximadamente, en Tripolitania, en el espacio comprendido entre Egipto y el actual Túnez, mientras que los occidentales se situarían en la región de Bugía que adquiriría un estatus de zona-frontera, según la definición ya otorgada por Ibn Jaldun [D. VALÉRIAN, Frontieres et territoires, p. 5] 
decide retomar los contactos diplomáticos con la Confederación catalanoaragonesa. Pedro el Ceremonioso se mostrará receptivo a la oferta, aunque persiste el escollo del tema tributario. En este ámbito, el monarca catalanoaragonés se muestra intransigente: Abu-1-Abbas deberá otorgar idénticas prestaciones a las otorgadas por sus antecesores, es decir, la concesión del tributo. Este pudo ser el verdadero motivo, de la interrupción de las negociaciones ${ }^{12}$. Las causas de la negativa a aceptar las condiciones impuestas por Pedro el Ceremonioso hay que buscarlas en la situación interna hafsí. Es evidente que la coyuntura política en Ifriqiya no era la misma en 1360, cuando Abu Ishaq aceptó el pago de un tributo anual. Abu-l-Abbas se encontraba, en 1371 , ante un estado prácticamente reconstituido y sin ningún tipo de amenaza exterior procedente del oeste magrebí. Sin embargo, el monarca catalanoaragonés continuará esgrimiendo, a pesar de la notable transformación geopolítica de Ifriqiya, las viejas argumentaciones para justificar la obligatoriedad del reembolso pecuniario.

En opinión de Dufourcq, a partir de 1373, los reiterados fracasos en los intentos de lograr la sumisión de Ifriqiya y la satisfacción de las parias, habían provocado un importante cambio en las directrices de la política exterior del monarca catalanoaragonés respecto a Túnez, que se materializará en una abierta hostilidad, cuyos primeros síntomas se habían empezado a poner en evidencia a finales de la década precedente. El reflejo de esta hostilidad, siempre según Dufourcq, podría ser ratificado por numerosos indicios documentales ${ }^{13}$.

Sin embargo, el aumento de las hostilidades, detectado en la documentación catalanoaragonesa del último cuarto del siglo XIV, vendría determinado, en realidad, por causas inherentes a la política exterior desarrollada en un primer momento por Abu-l-Abbas y continuada por su sucesor Abu Faris, no por un claro objetivo de Pedro III de cambiar sus directrices políticas respecto a Ifriqiya. A partir de la década de los 60 se observa a lo largo del litoral tunecino una intensificación de las actividades corsarias, cuyas principales bases, Bugía y Bona, estaban fuertemente protegidas y potenciadas desde el aparato estatal, que participaba de forma directa en los armamentos y en los beneficios que de estas actividades se derivaban ${ }^{14}$.

La reacción de las potencias europeas ante este aumento de la piratería musulmana desembocará en un periodo de confrontación directa: En 1390, se organiza una expedición franco-genovesa contra Madhiya; Y, en 1398-1399, se llevan a cabo las dos cruzadas valenciano-mallorquinas contra Tedelis y Bona, consecuencia de los pillajes perpetrados en 1397 por naves musulmanas

\footnotetext{
${ }^{12}$ Un análisis detallado de estas embajadas puede verse en M. D. LóPEZ PÉREZ, La Corona de Aragón y el Magreb, pp. 155-157.

${ }^{13}$ Sintetizadas en Ch.E. DuFOURCQ, Documents inédits sur la politique ifrikiyenne, pp. 30-34. 729.

${ }^{14}$ Cuestiones evaluadas por M. D. LÓPEz PÉREZ, La Corona de Aragón y el Magreb, pp. 705-
} 
armadas en Bugía ${ }^{15}$. En cualquier caso, la reacción hostil no tendría el efecto deseado, aunque habría de provocar finalmente un cambio de estrategia. El fracaso de las tentativas "cristianas" de acabar con los "nidos de piratas" supondrá un punto de inflexión en las relaciones diplomáticas entre Túnez y los estados mediterráneos, en general, y la Corona de Aragón, en particular. Las potencias europeas interesadas en el tráfico mediterráneo buscarán el marco de la negociación para mantener las relaciones pacíficas que propiciaran los intercambios.

En el campo de las relaciones entre la Corona de Aragón y la dinastía hafsí, existía otro importante punto de fricción, además del derivado del impago del tributo y el recrudecimiento de las actividades piráticas, como era la disputa por la posesión de las islas del golfo tunecino: Djerba, Kerkenna y Pantellaria. Un interés geoestratégico que había crecido a raíz de la conquista de Sicilia por Pedro el Grande. En esta coyuntura, será Djerba la que se erige como punto de fricción determinante en el deterioro de las relaciones. Los catalanoaragoneses habían conseguido recuperar su posesión en 1393, si bien en 1398 la isla vuelve nuevamente bajo la dependencia del soberano tunecino ${ }^{16}$.

La pérdida de Djerba y el pillaje de Torreblanca constituyeron los acontecimientos que culminan la escalada de las hostilidades. El franco deterioro de las relaciones se agrava además ante el aumento de las razzias piráticas perpetradas por los musulmanes cerca de las costas, en los mismos puertos e, incluso tierra adentro, con el consiguiente apresamiento de cautivos y la sangría monetaria que sus rescates significaban para la economía del país.

Antes de llevarse a efecto la cruzada de 1398-1399, Martín el Humano intentó liberar al mayor número posible de cautivos mediante la negociación. Así, cabe interpretar los preparativos de la embajada que se organizaba en junio de 1397. Los hermanos Pere (Honorat, Bernat y Castelló) fueron nombrados emisarios para tratar este tipo de cuestiones ante el rey de Túnez ${ }^{17}$. No sabemos si esta embajada fracasó o, sencillamente, no se llevó a cabo. El caso es que, un mes más tarde, en julio de 1397, los cautivos cristianos en Túnez pedían ayuda al monarca quien prometió enviarles a su consejero y camarlengo, Pere de Queralt, tan pronto regresara de Roma donde había sido enviado con motivo del Cisma ${ }^{18}$. Tras su vuelta, en enero de 1398, se iniciaron los preparativos, acordándose que sería la ciudad de Valencia la encargada de poner a punto una galera a disposición de los emisarios ${ }^{19}$.

\footnotetext{
${ }^{15}$ Cf. M. D. LÓPEz PÉREz, La Corona de Aragón y el Magreb, pp. 685-771.

${ }^{16}$ Sobre este tema $c f$. Louis de MAS LATRIE, Traités de paix et de commerce concernant les relations des chrétiens avec les arabes de l'Afrique septentrionale au Moyen Age, París, H. Plon, vol.I, pp. 249-251; R. BRUNSCHWIG, La Berberie orientale I, pp. 205-207; Salvatore FoDALE, pp. 79-80.

${ }^{17}$ Archivo de la Corona de Aragón (ACA), Cancillería (C), reg. 2242, f. 34 r. (Barcelona. 23, junio, 1397).

${ }^{18}$ ACA, C, reg. 2239, f. 29 v. (Barcelona. 1, julio, 1397).

${ }^{19}$ ACA, C, reg. 2239, f. 112 r. (Zaragoza. 13, enero, 1398).
} 
Además de la redención de cautivos cristianos, Pere de Queralt debía de tratar la restitución de las 'Sagradas Formas', robadas durante el saqueo de Torreblanca $^{20}$.

Sin embargo, éste no constituía uno de los objetivos primordiales, o al menos no era el único. Así se desprende de una carta enviada por Martín el Humano a su consejero Francesc de Casasaja, donde le notificaba que los cristianos cautivos en Túnez afirmaban que el sultán musulmán estaba dispuesto a liberarles y a devolver las 'Sagradas Formas' de Torreblanca, siempre que le enviaran un emisario dotado con el poder suficiente ${ }^{21}$. Junto a estas disposiciones, el rey de Túnez se comprometía, asimismo, a pagar un tributo anual de 3.000 dinares, a acordar una franquicia aduanera total para los mercaderes catalano-aragoneses y sicilianos, y a restituir la isla de Djerba al rey de Sicilia o, al menos, dejar que la reconquistara ${ }^{22}$.

No se llegó a ningún acuerdo definitivo y en agosto de 1398 los cruzados saqueaban Tedelis. ¿Por qué Tedelis? Es preciso recordar que los culpables del saqueo de Torreblanca fueron, parece ser, súbditos hafsíes, seguramente bugiotas. Sin embargo, Tedelis estaba en estos momentos en manos de los Zayyaníes, no de los Hafsíes. La hipótesis adelantada por Brunschwig, en base al contenido de una serie de documentos posteriores, parece plausible. Según dicho autor, el monarca de la Corona de Aragón temía irritar excesivamente al hafsí y, con ello, cortar cualquier posibilidad de negociación: el saqueo de Tedelis era un aviso ${ }^{23}$.

La consecuencia inmediata de estos ataques no se hizo esperar, ante la necesidad cada vez más evidente para ambas partes de que era indispensable acordar una tregua. La iniciativa partió conjuntamente de los dos sultanes norteafricanos, Abd Allah Abu Muhammad, rey de Tremecén, y Abu Faris, rey de Túnez, quienes elevaron la petición ante el monarca catalano-aragonés. La solicitud de entablar conversaciones sería aceptada por el rey tras deliberar con el consejo formado por los cinco mensajeros enviados por los jurados y prohombres de la ciudad de Valencia ${ }^{24}$. Los motivos aducidos por el consejo para aceptar la tregua residían en la conveniencia de establecer los acuerdos necesarios que permitieran rescatar a los cautivos cristianos en poder del rey de Túnez y que las anteriores negociaciones no habían conseguido llevar a término ${ }^{25}$.

\footnotetext{
${ }^{20}$ A. IVARS, Dos creuades, LXXX; R. BRUNSCHWIG, La Berbérie orientale, pp. 220-221; M.Teresa FERRER, La redempció de captius a la Corona catalana-aragonesa (s.XंIV), "Anuario de Estudios Medievales", 15 (1985), p. 250; J. SASTRE, Aportación (II), p. 486.

${ }^{21}$ ACA, C, reg. 2240, f. 72 r. (Zaragoza. 23, marzo, 1398).

${ }^{22} \mathrm{R}$. BRUNSCHWIG, La Berbérie orientale, I, p. 221.

${ }^{23} \mathrm{R}$. BRUNSCHWIG, La Berbérie orientale, I, pp. 220-221.

${ }^{24} \mathrm{ACA}, \mathrm{C}$, reg. 2242, f. 136 v. (Zaragoza. 17, abril, 1399).

${ }^{25}$ Según los informes presentados en la Corte, el número total de cautivos ascendía a unos 1.500 [Daniel GIRONA, Itinerari del rei en Marti (1396-1402), "Anuari de l'Institut d'Estudis Catalans", IV (1911-1912), doc. $30, \mathrm{p}$ 142; cit. M. T. FERRER, La redempció de captius, $\mathrm{p}_{\mathrm{i}} 250$; S. FODALE, Il riscatto, p.67]. Probablemente se trate de una cifra deliberadamente "hinchada" pero lo que si es cierto es que el mayor número de cautivos cristianos en el norte de Africa se localizaban en el reino de Tunez, sobre todo, en las ciudades de Bona y Bugía, clara consecuencia
} 
El embajador de la Corona era nuevamente Pere de Queralt ${ }^{26}$, mientras que el soberano tunecino nombraba a su vez, en categoría de representante, a su propio hijo Ibrahim ${ }^{27}$. No obstante, esta embajada sería suspendida, según se afirma en la documentación oficial, por considerarse más conveniente la realización de una segunda cruzada ${ }^{28}$.

El fracaso de las operaciones de castigo, tras el asalto de los cruzados a la ciudad de Bona en septiembre de 1399, vuelve a plantear la necesidad de llegar a un acuerdo con los sultanes norteafricanos. Se reinicían nuevamente las negociaciones, pero aquéllas serían interrumpidas por el pillaje de corsarios tunecinos en Terranova, Siciliaa ${ }^{29}$, en el mes de noviembre. Por su parte, el sultán hafsí intentará restablecer los contactos en la primavera siguiente, enviando como representante ante el rey de Aragón al médico judío Bonjuha Bondavi. Con todo, no será hasta 1402 cuando finalmente parta la embajada de Pere de Queralt ${ }^{30}$. Los capítulos que debía tratar como emisario de la Corona de Aragón se referían, en líneas generales, a la restitución de las reliquias robadas durante el saqueo de Torreblanca, la redención de cautivos, el pago de los tributos atrasados, la franquicia de derechos de aduanas, la devolución de la isla de Djerba al rey siciliano y la promesa de ayuda militar al sultán hafsí en contra de posibles enemigos a través del armamento de galeras o el aprovisionamiento de mercenarios ${ }^{31}$.

\section{LA FIRMA DE LA PAZ: EL ACUERDO DE 1403}

El resultado final nos es conocido: la firma del tratado de 1403. ¿Cuándo se llegó a concretar el acuerdo? No lo sabemos con exactitud. Brunschwig señala como fecha probable el mes de marzo, ya que a finales de dicho mes el contenido del tratado era conocido en Marsella ${ }^{32}$. En la Corona de Aragón no se haría pregón público de la concertación de la tregua hasta el mes de septiembre, al menos en la ciudad de Mallorca. Sin embargo, ya a partir del mes de mayo, se incluía a los musulmanes de Túnez, Constantina, Bona y Bugía entre las excepciones inherentes a las licencias de armamentos

del ya referido incremento de las acciones piráticas tunecinas.

${ }^{26}$ ACA, C, reg. 2242, f. 113 r. (Zaragoza. 4, mayo, 1399).

${ }^{27} \mathrm{ACA}, \mathrm{C}$, reg. 2242, f. 186 rv. (Zaragoza. noviembre, 1399).

${ }^{28}$ A. IVARS, Dos creuades, pp. 123-124, 130-131; R. BRUNSCHWIG, La Bérbérie orientale, pp. $222-223$.

${ }^{29}$ ACA, C, reg. 2242, f. 186 rv. (Zaragoza. 17, noviembre, 1399); A. IvARs, Dos creuades, p. CXXX, p. 159; R. BRUNSCHWIG, La Berbérie orientale, pp. 223-224.

${ }^{30} \mathrm{R}$. BRUNSCHWIG, La Bérbérie orientale, I, p. 224.

${ }^{31} \mathrm{ACA}, \mathrm{C}$ reg. 2244 ff. 156 v.-157 v. (1402); D. GIRONA, Itinerari del rei en Martí, 154,174,175,179,181; A. IVARS, Dos creuades, pp. 160-162.

${ }^{32}$ R. BRUNSCHWIG, La Berbérie orientale, I, p. 225. 
en corso $^{33}$ y se intentaba solventar cualquier tipo de apresamiento indebido, a fin de evitar una ruptura prematura de la tregua ${ }^{34}$.

Precisamente es ese pregón público, ordenado por el gobernador de Mallorca, Roger de Moncada y promulgado el 6 de septiembre, el que hemos utilizado como base documental. Conservado en el Archivo del Reino de Mallorca $^{35}$ fue objeto de una primera publicación a principios del siglo XX por E. Aguiló ${ }^{36}$. La importancia del documento para el análisis de las relaciones entre la Corona de Aragón y Túnez en el tránsito de los siglos XIV y XV nos induce a reforzar la exposición de su contenido con anotaciones al texto original conforme a los usos de transcripción actuales.

El tratado está compuesto por cincuenta y dos capítulos en los que se intentará buscar una solución negociada a los principales puntos de fricción existentes entre los dos estados, tanto por cuestiones de carácter económico como, sobre todo de índole política y social.

El primero de los temas tratados se ocupa del siempre espinoso tema de las islas de Djerba y Pantelleria ${ }^{37}$. Sobre la reivindicación de la isla de

${ }^{33}$ Nos referimos a los mismos ejemplos mencionados con motivo de la hipotética firma de un acuerdo entre la Corona de Aragôn y el reino de Tremecén en 1403 y que reproducimos en el capítulo anterior.

${ }^{34}$ Así, Roger de Montcadạ, como gobernador del reino de Mallorca, decretó la liberación de Abd Allah ibn Hamet Alcaminer, de Túnez, capturado en los mares de Benigenet, en el reino de Tremecén, junto a otros musulmanes considerados de buena guerra, por una galera armada en Barcelona. Los motivos que aduce son la conservación de la paz existente entre el rey de Aragón y el soberano hafsí y los buenos tratos de que eran objeto los súbditos catalano-aragoneses en el reino de Túnez [Archivo del Reino de Mallorca (ARM), Lletres Comunes (LLC),82, f. 86 r. (Mallorca. 21, mayo, 1403). En este mismo contexto se inscribe el guiatge concedido por Nicolau Pujades, como baile general del reino de Valencia, a Muhammad ibn Muhammad y Muhammad Alhaig, del reino de Túnez, capturados injustamente a tenor de la tregua establecida entre los soberanos de ambos estados. Su vigencia finalizaba una vez desembarcados los dos musulmanes en tierra tunecina, tras realizar el trayecto vía Barcelona [Archivo del Reino de Valencia (ARV), Real Patrimonio,'(RP), Batllia, 1144, f. 35 r. (Valencia. 25, julio, 1404)].

${ }^{35}$ ARM, Pregons, 421, ff.129 r.-134 v. [= Pregón Mallorca, 6.09.1403]

${ }^{36}$ E. Aguiló, Pau feta entre els reys d'Aragó, p. 350.

37 “En lo nom del nostre Senyor sia, amén. A perpetual memòria de la bona e vera pau et tranquil.litat entre los molt excel.lents prínceps e senyors los senyors en Martí, per la gràcia de Déu rey d'Aragó, e en Martí, rey de Cićlilia, primogènit del dit senyor rey, de una part, e lo molt excel.lent Moley Buffares, rey de Tunis, de Xarch e del Garb e de tota la Barbaria, de la altra, feta e fermada e en per tostemps valedora, lo noble Moley Ethec Benbuibel, lochtinent e procurador en aquestes coses del dit excel.lent rey de Tunis, havent de acò ple poder del dit magnífich rey, de una part, e lo noble mossèn Pere de Caralt, cavaller, ambaxador e missatger special del dit senyor nostre rey, han feta e fermada la dita pau e tranquil.litat entre los dits senyors e tots los sotmeses d'aquells en la forma e manera qui.s seguex.

E primerament que en la dita pau feta entre los dits senyors reys e ab lurs regnes e regiments, terres, lochs e ylles en aquells adjaents, sien ara de present compreses, enteses e nomenades les ylles de Gerba e les ylles de la Pantaneleya; emperò que sia legut al dit rey de Cicília aprés cinch anys en l'esdevenidor, ab armada o stol, e no per via de cors ne per cosssarị o altres guerres poques, pendre o fer pendre la dita ylla; e que lo dit senyor rey de Cicília sia tengut lo dit stol o armada, aprés $V$ anys en l'esdevenidor axi com dit és, per sis meses ans que la dita armada o stol vinga a la dita ylla de Gerba, intimar o fer intimar per letres públiques ab testimoni roborades, o per missatger digne de fe en aquestes coses spacialment diputat, al dit excel.lent rey de Tunis o al seu succehidor o lochtinent, o succehidors o lochtinents. E per semblant lo dit rey de Tunis pusca pendre o fer pendre per stol o armada, aprés V anys en l'esdevenidor, la ylla de Pantenalea, per V meses aprés los V anys en l'esdevenidor; en axî emperò que.l dit rey de Tunis sia tengut intimar o fer intimar per ses letres dignes de fe o per missatger digne de fe en açò specialment deputat, aprés V anys aprés feta la dita pau e aprés sis meses següents, al dit senyor rey de Cicília o al dit succehidor o lochtinent o succehidors o lochtinents e aquell, ans que.l dit stol o armada del dit rey de Tunis vinga pendre l'ylla de la Pantanalea, e no en altre manera per cossaris o guerres poques, la dita pau e concòrdia entre los 
Djerba - recordemos, de nuevo en poder hafsí desde 1398- se concretó el derecho del rey de Sicilia a conquistarla tras concluir el período de vigencia de la tregua, es decir, pasados cinco años, mediante un aviso previo de seis meses; En contrapartida, el rey de Túnez gozaba de idénticas prerrogativas para apoderarse de la isla de Pantelleria. Una decisión, sin duda, salomónica, que preservaba la cordialidad de las relaciones durante el período previsto de tregua.

El segundo tema que registra el tratado está destinado a regular el problema de la redención de cautivos y las condiciones en que ésta debía llevarse a cabo. Los capítulos exponen detalladamente las posibles situaciones de fraudes, desde la prohibición de la venta ilegal a la imposición de precios de rescate abusivos, una compensación que debía estar en relación a las cantidades de compra acordadas ${ }^{38}$. A tal efecto, se consideraba que debía prevalecer el valor de la primera venta, la realizada a su llegada, a fin de que frau alcun o engan no.s puxa fer en los contractes. Por otra parte, la situación del cautivo había de mejorar notablemente mientras llega el rescate, ya que se determina la obligación de ser "desferrats", es decir, quitarles las cadenas, siempre y cuando encuentren avales suficientes que cubran su fuga o el precio de su rescate. Se procura, asimismo, facilitar la salida al eximirlos del pago de cualquier impuesto de aduanas ${ }^{39}$. Consideración que se hace extensiva a la importación de moneda necesaria para sufragar estos rescates que también

dits senyors e prínceps feta no contrestant, ans romanga en sa forsa e valor" [Pregón Mallorça, $6.09 .1403]$. En ambos casos se especifica que la toma de las islas, sea Djerba, sea Pantelleria, deberá realizarse "ab armada o stol, e no per via de cors ne per cossaris o altres guerres poques", es decir, se rechaza la posibilidad de conquista a través de guerra encubierta.

38“II - Ítem, con sia devengut en la dita pau e concòrdia dels catius axí cristians com serreyns, sots certs pactes demunts anotats, que los dits princeps reys e senyors sien tenguts en continent aprés intimació feta a aquells, manar o fer manar per tots los regnes d'equells que los dits catius axí cristians com sarrayns no sien trets o transportats públicament o amagada fora los regnes o regiments d'equells per qualsevol persones de qualsevol dignitat sien sots certa pena a volentat dels dits senyors reys imposadora.

III - Item, que si alcun senyor o patró d'alcun catiu axí cristià com moro vendrà o alienarà o traurà o traurre farà, per malícia o ignorament, lo seu catiu de la senyoria dels dits reys sens que en assò comès haurà aytant com serà lo preu del dit catiu, e serà aplicat a la cort o cófrens del rey son senyor.

IIII - Item, que con molts patrons o senyors axí serrayns com cristians hagen comprats los catius lurs en una venda e preu, axí com són pare, mare e fills e altres stranys, so és per L, per cent o per CC o per semblants preus, dobles o florins de la moneda qui corre en la terra, e alcun o alcuns d'equells catius seran morts o seran tornats moros o cristians, que lo preu d'equells se pach e la remsó per caps, e no la hun més que l'altre ne per lo tot" [Pregón Mallorca, 6.09.1403]

39 “VII - Ítem, los patrons o senyors dels catius axí serrayns com cristians no pusquen demanar per remsó d'equells més avant del preu de la primera venda feta de aquells per los primers patrons o senyors en lo temps que forren portats catius de terra de cristians en terrra de moros, 0 de terra de moros en terra de cristians; e assò per tal que frau alcun o engan no.s puxa fer en los contractes e sia tolta matèria e discòrdia en l'esdevenidor o dels temps de la dita pau feta a avant.

VIII - Ítem, que dementre los dits catius axí serrayns com cristians seran en poder de lurs senyors e lo preu e remsó d'equells tardarà, e los dits catius trobaran fermanses per fuyta o per lo preu de lur remsó, que aytals sien desferrats e stiguen sens ferre, emperò que entre tant paguen setmana a lurs senyors.

VIIII - Item, que tots los catius axí cristians com sarreyns qui sien sots potestat e senyoria dels dits reys d'Arago, de Cicília e de Tunis, del temps de la dita pau a avant no sien tenguts pagar duana, portes, mangeries o altre qualsevol imposició per lur exida, mas pagat lur rescat o preu de lur remsó pusquen francament exir e passar del loch on serà a tota lur volentat" [Pregón Mallorca, $6.09 .1403]$ 
queda exenta del pago de la 'dècima' (la décima parte de la cuantía importada $a^{40}$ y de cualquier otro impuesto que pudiera cobrarse sobre la entrada-salida de monedas. Finalmente, una vez redimidos, es decir, sufragado su rescate, los cautivos tendrán plena libertad de movimientos, tanto de sus personas como de sus escasas pertenencias. No hay duda de que el tratado intentaba favorecer el trasvase de la población cautiva, sea musulmana, sea cristiana, hacia sus diferentes lugares de origen.

No obstante, es probable que la mayoría de la población cautiva a la que van dirigidas están cláusulas sea mayoritariamente cristiana, ya que la comunidad esclava tunecina en territorios de la Corona de Aragón había de ser notablemente inferior. Esta hipótesis, sin duda arriesgada, se sustenta en una doble consideración. La primera responde al notable incremento de la piratería tunecina a partir de la década de los 60-70, que se había convertido a finales de siglo en un factor asfixiante para el comercio. En segundo término, la continua amenaza en que vive la población que habitaba en áreas de litoral, especialmente en las costas mallorquinas. Ello no significa, naturalmente, que los corsarios catalanoaragoneses no ejerciesen su oficio contra embarcaciones hafsíes o los habitantes del litoral, pero la presión que ejercieron debió ser menor. La confirmación de esta hipótesis parece encontrarse en el propio tratado. El capítulo XIII dice expresamente: Item, que en tots los capitols demunt dits on son nomenats catius sien enteses los catius del dit rey de Tunis axí com los catius de las persones e sotmeses seus, exceptat emperò que los catius del dit rey de Tunis no paguen sinó sinquanta dobles per cap. En ningún momento, el articulado hace mención expresa a los cautivos en territorio catalanoaragonés. El problema del cautiverio, a principios del XV, parece corresponder fundamentalmente al ámbito hafsí. Remarquemos, además, cómo los cautivos en poder del sultán tienen un límite en la cuantía de su rescate: 50 dinares.

La situación de la infancia cautiva también es objeto de una detallada regulación. Los niños nacidos en cautividad deberán pagar un rescate, pero si son menores de 10 años la cuantía se reduce a la mitad de sus padres; Mientras que las mujeres ya embarazadas el día de la confirmación de la tregua verán cómo sus hijos serán considerados ya libres antes de nacer ${ }^{41}$.

\footnotetext{
${ }^{40}$ Idéntico porcentaje al abonado por el resto de mercancías, como analizaremos más adelante. "X - Item, que de la moneda que serà portada de las terras dels dits senyors reys d'Aragó, e de Cicília en les terras del dit rey de Tunis, e de la moneda que serà portada de las terras dệ dit rey de Tunis en les terres dels dits reys d'Aragó e de Cicília, per remsó dels catius, axí cristians com moros, no sia pagada dècima ne alcun dret acustumat de pagar de semblants monedes.

XI - Item, tots los catius axí sarreyns com cristians pus que hagen pagat lur preu o remsó pusquen francament e sens contradicció d'alcun exir dels lochs on seran e anar on se volran ab totes lurs robes, monedes e béns.

XII - Item, si alcun patró ccristià̀ o serrayn haurà I o molts cạtius e I d'equells se volrà rembre que son patró o senyor no li puxa contredir per alcuna occasió o çausa, posat que molts catiụs hage comprats en una compra, ans cascun catiu pach lo preu que li pertany per la sua part e sia desliurat de tota servitut, no contrestant que molts ensemps ne hage comprats en una compra" [Pregón Mallorca, 6.09.1403]

"41 "V - Ítem, sia de benignitạt, largitat e reyal gràcia que los infants axí cristians como moros qui son stats engendrats en catiu stants lurs pares e mares catius per totes les terres e senyorius dels dits reys, e sien de edat de $\mathrm{X}$ anys en avall no deguen ne sien tenguts pagar per lur remsó o rescat sinó la maytat, o aytant com és lo mig de la compra de lurs pares o de lurs mares. Item,
} 
El resto de los acuerdos son de índole económica. Como era habitual ya desde los primeros tratados del siglo XIII, se concede la salvaguarda real a todos los súbditos de la Corona de Aragón y Sicilia en Túnez, aplicándose las obligaciones derivadas de esta protección $\mathrm{n}^{42}$. Cabe hacer notar que no existe reciprocidad, es decir, la salvaguarda de los súbditos tunecinos se posterga hasta casi el final del tratado, en el cap. XLVIII. Una diferencia sustancial en relación a los tratados firmados en el siglo XIII y también en el XIV en los que las cláusulas de protección se acuerdan en igualdad de condiciones. No obstante, las obligaciones proteccionistas del sultán de Túnez tienen una excepción que aparece claramente explicitada en el capítulo XV del tratado ${ }^{43}$. Se trata del supuesto en que el ataque sobre puertos y territorios tunecinos sea perpetrado por enemigos de la Corona de Aragón y Sicilia. De producirse estos hechos, la aduana no estará obligada a resarcir los daños perpetrados en bienes o personas catalanoaragonesas o sicilianas. Sin embargo, no se especifica ninguna situación a la inversa, lo que parece demostrar, de forma indirecta, junto con la escasa relevancia que se otorga a la salvaguarda relegada al final del acuerdo, la escasa presencia de operadores de Túnez en territorios bajo jurisdicción de la Corona de Aragón o de Sicilia. Ello no significa que no intervinieran, aunque es evidente que ni la colonia ni el volumen de operaciones debía ser lo suficientemente importante como para incluirlos en un capítulo específico del tratado ${ }^{44}$. Se reconoce, eso sí, la legalidad de reclamar posibles cantidades adeudadas por cristianos o musulmanes con la condición expresa de estar en paz con el rey de Túnez. En ese caso, la propia aduana tiene jurisdicción para iniciar los trámites de reclamación de deudas, incluso de reparación de injurias.

que alcuna fembra.

VI - Item, que les mares axí serraynes com cristianes del die de la dita pau confermada seran prenys, que los lurs prenyats sien vertadés franchs e deliures de tota captivitat" [Pregón Mallorca,
6.09 .1403 ]

42"XIIII - Ítem, que tots los catalans e cicilians e tots los sotsmeses dels dits reys de Aragó e de Cicília vinents o aportants a Tunis e a totes les altres terras sotsmeses al dit rey, les quals lo dit Rey ara senyorege e d'equi avant senyoregerà, sien sauls e sagurs en béns, en persones, e en or, en argent e en tots lurs havers axí vinent, stant, mercadejant, negociant e d'equi partint, e que en alcun loch de la sua senyoria no hage naufraig ans si alcun navili rumpia en alcun loch de la sua senyoria, que tots sien sauls e sagurs en persones, robes, argent, or e haver d'equells" [Pregón Mallorca, 6.09.1403]

43 “XV - Ítem, que si per ventura s'esdevenia que en lo port de Tunis o en altre port, terra o loch del dịt rey de Tunis, los catalans o cicílians o altres sotsmeses dels reys d'Eragó o de Cicília eren ultrajats o dampnificats per lurs enemichs en béns o en persones, que la duana del dit rey de Tunis ne del loch on seran dampnificats, no sia tenguda fer alcuna asmena dels dits dans e dapnatges resabuts; $\mathrm{e}$ per semblant si enemichs del dit rey de Tunis faran ultratge o dampnificaran en béns o en persones los sotsmesos del dit rey en los port de Tunis o altre de la sua senyoria, que los catalans e cicilians sotsmesos del dits senyors reys d'Aragó e de Sicília no sien tenguts a fer alcuna asmena dels dans a aquells donats.

XVI - Item, si alcun català o sicilià 0 sotsmès dels dits senyors reys d'Aragó e de Sicília haurà a rebre o demanar alcun deute o.s volrà clamar de alcun deute, drets o asmena d'alcun sarreyn o d'alcun cristià qui sia sots pau del dit rey de Tunis, que la duana del dit Rey sia tengụda fer rahó e justícia e spetxar aytal català o sicilià del seu crèdit, axí dels deutes com de injúries" [Pregón Mallorca, 6.09.1403].

${ }^{44}$ Sobre la presencia de operadores magrebíes, no solamente procedentes de territorios hafsíes, sino también zayyaníes y mariníes $c f$. M.D. LóPEZ, La Corona de Aragón y el Magreb, 346-399. 
Un número importante de capítulos están destinados a regular la organización de la alhóndiga. Los acuerdos estipulan la edificación de nuevos equipamientos para los comerciantes de la Corona de Aragón, quedando la antigua instalación destinada a los sicilianos. En el tratado de 1360, la traducción del acuerdo aportada por Alarcón y García de Linares estipula que se les construirán alhóndigas propias para su alojamiento en la excelsa corte [de Túnez] acondicionándose convenientemente sus habitaciones y almacenes, y no podrá habitar con ellos persona alguna extraña a su nación, sino con su consentimiento" ${ }^{45}$. La especificación "se les construirán alhóndigas propias", ¿qué significa? Es probable que las construcciones precedentes se hallasen en un estado deficiente; Además, el continuado incremento del volumen de negocios catalanoaragoneses en Túnez, había decidido al sultán a acometer la empresa de contruir un nuevo edificio.

En el tratado de 1403 se da por supuesto que la alhóndiga existe ${ }^{46}$. ¿Se trataba de la nueva instalación, acordada en 1360, o, simplemente, aquélla no había llegado a construirse? No lo sabemos, únicamente se especifica que la ya existente quedaría en manos de los sicilianos. El nuevo edificio se costearía, como era habitual, con los ingresos de la aduana. Aunque no se menciona, la costumbre establecía que los gastos se cubrirían con una parte de los tributos abonados por los mercaderes beneficiarios: catalanoaragoneses, genoveses, venecianos. Por el contrario, se especifíca que la nueva construcción ha de ser de dimensiones considerables, de gran altura, de manera que alcun no y puxa entrar sinó per la porta del dit alfòndech. Los derechos de jurisdicción, ya reconocidos por la costumbre, quedan igualmente estipulados al especificar que alcun no gos entrar en lo dit alfòndech sens licència dels cònsols dels catalans e sicilians; e que los porters sien tals que puxen vedar als sarreyns e totes altres persones que no.y entren sens volentat dels cònsols e dels mercaders.

A partir del tratado, catalanes y sicilianos dispondrían de cónsules diferenciados. Los cónsules tendrán obligación de impartir justicia entre sus súbditos, pero también, como queda especificado en los acuerdos, cuando así lo reclame cualquier musulmán ${ }^{47}$. En caso de recusación, el musulmán

\footnotetext{
${ }^{45}$ M. Alarcón, R. García de LinARes, Los documentos árabes, doc. 140 bis, p. 318.

46“XVII - Ítem, que los catalans e sicilians e los sotsmeses dels dits reys de Sicília e d'Aragó hagen en Tunis e en les altres terras del dit Rey de Tunis alfóndechs per lur habitació, ab botiges, forns e totes jurisdiccions e sgleya; e que alcuna persona stranya no.y puxa star o habitar sino ab volentat d'equells catalans o sicilians; e sia tenguda la duana en la edificació dels dits alfóndechs treballar, adobar, pagar e despendre de les monedes de la dita duana axí com és acustumat.

XVIII - İtem, que los sicilians e los sotsmeses del rey de Cić́lia hagen l'alfòndech antich o sia edificat altre semblant d'equell a massió de la duana, e que sia de ten gran altitut que alcun no.y puxa entrar sinó per la porta del dit alfòndech; e que alcun no gos entrar en lo dit alfòndech sens licència dels cònsols dels catalans e sicilians; e que los porters sien tals que puxen vedar als" sarreyns e totes altres persones que no.y entren sens volentat dels consols e dels mercaders" [Pregón Mallorca, 6.09.1403]

47 “XVIIII - Ítem, que los catalans hagen I cònsol e los sicilians altre cònsol qui fassen rahó e justícia entre aquells; e si alcun sarreyn se clama d'alcun català o sicilià o d'alcun sotsmès als dịts reys d'Arago e de Cicília sia tengut aquell requerir denant lo cônsol dẹls catalans o dels sicilians, e lo dit cònsol sia tengut aquell spetxar e fer-li fer rahó e justícia; e si assò lo dit cònsol fer no volrà, lavors lo sarreyn se pusca clamar en la duana; e si alcun català o sicilià o habitador en lur regiment volrà demanar o haver d'alcun sarreyn o d'altre qualsevol qui sia sots pau del dit
} 
siempre podrá recurrir a la aduana. El recurso ante la aduana es, además, el procedimiento ordinario al que deben acudir los súbditos catalanoaragoneses y sicilianos en caso de conflicto con tunecinos o cualquier otro en paz con el rey de Túnez. Por su parte, a los cónsules se les concede, igualmente, la prerrogativa de exponer sus quejas ante el soberano hafsí una vez por semana.

La cuestión fiscal también es regulada, aunque de forma breve, lo que introduce algunos problemas de interpretación, si comparamos sus disposiciones con las fuentes coetáneas. Por regla general, sabemos que los intercambios de mercancías, no únicamente en territorio hafsí, sino toda el área magrebí, debían realizarse en aquellos puertos donde existía un control aduanero. Las razones resultan obvias: los impuestos derivados de las transacciones constituyen una de las principales fuentes de sostenimiento económico de los estados norteafricanos ${ }^{48}$. Por ese motivo era preciso concentrar los puntos de percepción para ejercer un control exhaustivo que limitase el fraude y el contrabando. De hecho, en el acuerdo de 1403 se contempla la posibilidad de introducción de moneda falsa y las medidas a adoptar por los agentes aduaneros. Dichas prácticas debieron ser habituales, desde el momento en que los acuerdos se hacen eco de la cuestión.

Los tratados mencionan, en ocasiones, las cuantías de los gravámenes, si bien los enunciados resultan insuficientes para poder valorar con exactitud la incidencia de las tasas sobre el valor de las mercancías objeto de transacción. El motivo no es otro que las notables diferencias existentes tanto en el origen como en el puerto de desembarco, aunque cabe tener presente además las coyunturas políticas y económicas específicas.

En el acuerdo de 1403, se estipula como imposición general el 'dezè' (la décima parte) de las mercancías importadas en territorio tunecino, con la excepción de oro y plata que sólo abonan 'mig dezè', es decir, un 5\%. Hasta aquí nada nuevo ${ }^{49}$. Estamos ante porcentajes habituales, salvo excepciones, ya

rey de Tunis, lavors los catalans o sicilians o habitadors sots lur regiment e destret deguen demanar lur rahó en la duana, e la duana sia tenguda fer rahó e spetxar aquells.

$\mathrm{XX}$ - Item, que los cònsols dels catalans e dels sicilians pusquen visitar la reyal magestat del rey de Tunis una vagada la setmana, e sia.ls dada entrada manifesta sens alcun contrast, per so que puxen notifiçar lo ésser e la condició dels mercaders çatalans e siçilians; e açò los sia fet e atorgat per prerogativa e honor dels dits senyors reys d'Aragó e de Sicília” [Pregón Mallorca, 6.09.1403]

${ }^{48}$ Son pocas las noticias conservadas pero resultan sumamente significativas. Brunschvig señala que en el XV la aduana de Túnez ingresaba anualmente en las arcas dẹl sultán 170.000 dinares de oro, un tercio de sus entradas globales [R. BRUNSCHWIG, La Bérberie orientale, $\mathrm{t}$. II, p. 73, nota 1, p. 243].

49"XXI - Ítem, que tots los catalans e sicilians e altres sotsmeses dels dits senyors reys d'Aragọ e de Sicília no paguen sinó lo dezè ten solament de les robes e mercaderies que vendran en Tunis o en altres lochs o terres del dit rey de Tunis.

XXII - Item, que los catalans e sicilians e tots los sotsmeses dels dits senyors rey d'Aragó e de Sićlia no paguen ne deguen pagar de or, d'argent, dobles o millaresos sinó ten solament mig dezè sens altre, addició.

XXIII - Item, que si alcun català, șicilià, o altre sotsmès dels senyors reys d'Aragó e de Sicília portarà millaresos falsos qui no sien de la liga del rey de Tunis e vendran en mans de l'official de la duana, aquell official puxa los dits millaresos pendre, e si-s volrà, aquells teyar e pendre.n mig dezè e aprés retre e restituir lo romanent a aquell de qui seran los dits millaresos" [Pregón Mallorca, 6.09.1403] 
desde la segunda mitad del XIII ${ }^{50}$. Por otra parte, se concreta el precio de venta, que será el corriente en los mercados de origen, es decir, en la Corona de Aragón y Sicilia, dejando de esta forma en manos de los operadores europeos el control de los precios ${ }^{51}$. Los impuestos, dice también el acuerdo, no deberán abonarse hasta dos meses después de producirse la venta, y en caso de impago será la propia aduana la que intervendrá para forzar el abono de las cuantías. Si aún así resulta imposible el pago, las mercancías quedarán exentas de tasas fiscales. Igualmente, se estipula que aquellas mercancías, incluidas piedras preciosas, perlas y esmeraldas, oro y plata, que no sean vendidas, podrán salir nuevamente del país, quedando libres del pago de cualquier tipo de imposición.

En lo que respecta a las exportaciones, no existe, como norma general, ninguna tasa por derechos de exportación. El acuerdo de 1403 establece, específicamente, que se puedan comprar y extraer del territorio, libres del pago de impuestos, el equivalente a las mercancías importadas ${ }^{52}$. Y se añaden prerrogativas idénticas, es decir, exención de tasas, para aquellas mercaderías cuya cantidad era equivalente a la capacidad de carga de los fletes negociados en las embarcaciones. Son las mismas condiciones reseñadas por Pegolotti en su célebre manual y que se sitúan en la primera mitad del XIV. Según este operador italiano, al hacer referencia a la aduana de Túnez, explica que Chi ne trae tanto quanto à mezzo non paga nulla, ma chi trae e non à mezo paga mezzo diritto ${ }^{53}$, lo cual no deja de ser un mecanismo de fomento

${ }^{50} \mathrm{El}$ tratado de 1271 , firmado entre Jaime I y al-Mustansir de Túnez, certifica ese $10 \%$, al igual que el suscrito en 1285 entre Pedro el Grande y el tunecino Abu Hafs, o el de 1314 entre Jaime II de Cataluña-Aragón e Ibn al-Liyhani de Túnez [M. L. DE MAS LATRIE, Traités de paix et de commerce, vol.II, p. p: 280-284, 286-290, 306-310]. Anselmo Adorno, en la descripción que nos ofrece a raíz de un viaje realizado en 1470, cifra en un $10 \%$ los impuestos sufragados por los mercaderes europeos en las aduanas de Túnez: "En continuant le long du Lac, on trouve un autre bâtiment au-dessus du Lac appelé la Douane. Toutes les marchandises qui viennent de la mer ou de la cité y sont entreposées et paient un tonlieu de dix pour cent: une pièce d'étoffe sur dix, un ducat ou un doublon sur dix et ainsi de suite" [J. HEERS, Itinéraire d'Anselme Adorno, pp.105107]. Idénticas constataciones se derivan del análisis de los acuerdos establecidos entre los estados italianos y los sultanatos magrebíes, según ha remarcado G. JEHEL, L'Italie et le Maghreb au Moyen Age, pp. 113-116].

51 "XXIIII - Ítem, que les mercaderies e les coses e robes que vendran o seran portades en la duana del rey de Tunis o en tot altre loch de la sua senyoria per los catalans, sicilians o sotsmesos dels dits senyors reys d'Aragó e de Sicília no degen esser stimades ne apreciades sinó en aquell preu que les dites robes e mercaderies comunament valen per la sua terra e segons cors de la terra; $\mathrm{e}$ sobre assò no.ls sia feta forsa alcuna; e que no paguen aquell dret $\mathrm{o}$ mig dret que deuen o son tenguts pagar per les dites robes e mercaderies fins a dos meses passats del die de la dita venda prop vinents; ${ }^{e}$ si de las mercaderies que vendran no poden ésser pagats, la duana sia tenguda fer los pagar per lo comprador e lavores sia tengut de pagar lo dret; es si no son pagats de las mercaderies que hauran venudes, que no sien tenguts pagar alcun dezê de las dites coses. XXV - Item, si alcun català, sicilià o altre sotsmès dels senyors Reys d'Aragó e de Sicília portarà alcunes mercaderies, pedres precioses, perles o maracdes, or o argent 0 altres robes 0 mercaderies, en alcun loch o terra de la senyoria del dit rey de Tunis, e les dites coses e mercaderies vendre no volrà, que no sia forsat vendre aquelles, ans li sia legut e se.n pusca les dites robes e mercaderies tornar e portar en qualsevol loch se volrà, e d'equellas no sia tengut pagar alcun dret" [Pregón Mallorca, 6.09.1403].

52" XXVI - Ítem, que de totes aquellas coses que los catalans e sicilians hauran venudes e hauran pagat dret pusquen comprar e traure de la terra altres mercaderies per tanta quantitat com hauran venut, e no sien tenguts pagar alcun dret" [Pregón Mallorca, 6.09.1403].

${ }^{53}$ Francesco BALducCI PEgOlotTi, La pratica della mercatura, ed. A. Evans, New York: Kraus Reprint, 1970, p. 132. 
de las importanciones y, en consecuencia, de abastecimiento de los mercados tunecinos.

Se regula igualmente la compra de naves y mercancías cristianas, diferenciando si el comprador procede de un territorio enemigo del rey de Túnez o por el contrario con el que existe una tregua ${ }^{54}$. En el primer caso, el comprador del navío deberá pagar las tasas acostumbradas, mientras que en el segundo estará exento del pago de impuestos. Las ventas entre catalanoaragoneses y sicilianos o, en general, las establecidas con otros mercaderes cristianos tampoco se verán gravadas por la aduana ${ }^{55}$.

Las tarifas aduaneras se abonaban, en consecuencia, una única vez y tenían vigencia en toda el área sometida al rey de Túnez, por lo que se ratifica que se trataba de una práctica habitual ya desde el s.XIII ${ }^{56}$ en lo que se refiere a los territorios hafsíes ${ }^{57}$.

Una parte, no menos importante, de los capítulos del tratado se consagra a regular los mecanismos de compra-venta y a velar por la correcta

54“XXVII - Ítem, que los catalans e sicilians pusquen comprar dels nòlits que hauran dels navilis de galeas e de naus lur, aquellas mercaderies que.s volran en les terres de la senyoria del dit rey de Tunis, e d'equelles mercaderies no paguen alcun dret.

XXVIII - Item, si alcun català, sicilià o altre qui sia del destret de catalans o sicilians vendrà alcun sarreyn o cristià, qui sia sots pau del dit rey de Tunis, nau, galera o altre navili, no sien tenguts pagar alcun dret ne mig dret, e pusquen comprar legudament dels preus de les dites fustes o navilis que vendran qualsevol coses e mercaderies sens pagar alcun dret; e si alcun qui no sia sots pau de la senyoria del dit rey de Tunis compraran los dits navilis que pach lo dret pertanyent del preu de la venda dels dits navilis" [Pregón Mallorca, 6.09.1403].

55 "XXVIIII - Ítem, que si catalans o sicilians vendran entre ells alcunes coses o mercaderies 0 a altres cristians, no sien tenguts pagar alcun dret si lo venedor serà català 0 altre cristià.

$\mathrm{XXX}$ - Item, que si alcun català o sicilià o altre qui sia de lur destret vendrà alcunes mercaderies en les terres de la senyoria del rey de Tunis e volrà anar o passar en altres terres sotsmeses al dit rey de Tunis, pusca assò fer francament e sens contrast, e anar e comprar aquellas coses que volrà; e de sô que vendrà la duana sia tenguda fer al dit venedor carta testimonial que pusca comprar e portar les coses e mercaderies que volrà sens que no pach alcun dret e axí mateix pusca lo dit venedor fer procurador qui compre per ell, e que.l dit procurador no pach alcun dret" [Pregón Mallorca, 6.09.1403].

${ }^{56} \mathrm{El}$ tratado de 1314, firmado por Jaime II de la Corona de Aragón y el sultán de Bugía Abu Bakr hace mención expresa a estas circunstancias y establece la obligatoriedad de un úniço pago en el conjunto de aduanas del territorio bujiota [M. L. DE MAS LATRIE, Traités de paix et de commerce, pp. 304-306]. La documentación matlorquina proporciona, en este sentido, pruebas irrefutables. Úna reclamación elevada ante las autoridades de Bugía en 1332 certifica el pago doble al que fueron obligados dos mercaderes mallorquines, Berenguer Cerdà y Mosse ben Haron, primero en la aduana de Djidjelli, después en la de Bona, por las mismas mercancías. El lugarteniente de Mallorca alega que "la qual cosa no par raonable, que els dits mercaders de lurs mercaderies degen pagar pret II vegades; e serà contra la tenor e forma de la pau feta entre lo nostre senyor rey de Mallorques e el molt alt rey de Tonis e les gents dels dits senyors reys" La petición es clara: la restitución de los derechos abonados en la primera de las plazas, en Djidjelli Antoni PONS, Los judíos del reino de Mallorca durante los siglos XIII y XIV, Palma de Mallorca: Ed. Miquel Font, vol.II, doc.88, pp. 269-270].

${ }^{57}$ En el sultanato mariní, sin embargo parece existir la obligatoriedad de pagar nuevamente los derechos en determinadas plazas. Así parecen poder interpretarse afirmaciones de Pegolotti referentes a los impuestos a sufragar en Safi -"Di ciò che vi metti d'avere paghi 10 per centenaio in roba; oltre a ciô paghi uno altro diritto che si chiama mangona, la quale si paga il sedecimo di ciò che la mercatantia è stimata, e questa cortale mercatantia pagato che abbi questi denari sì la puoi portare per tutto lo reame sanza pagare più mangona, ma il decimo si paga in ogni sua buona terra, cioè in Morrocco e in Michelenza e in Fies e in Rabatta -nell'altre terre non ne dànno danaịo. E si la porti da una terra a un'altra sì ti conviene portare albara, cioè póliza della dogana del signore, per potree mostrare onde la recasti" - o en la plaza de Niffe, donde al referirse al impuesto de la intalacca afirma que "poi la puoi portare per tutto lo reame ove ti piace sanza pagare altro diritto salyo in Morrocco e in Michelenza e in Fiesso e in Rabatta, chè in queste 4 terre paghi come in Niffe" [Francesco BALDUCCI PEGOLOTTI, La pratica della mercatura, pp.
274,275 . 
realización de las operaciones mercantiles. La intervención de trujamanes y corredores aparece detallada, estipulándose que las ventas realizadas por mediación de estos agentes deberán hacerse con el aval de la aduana, mientras que aquéllas en las cuales no se precisa su mediación, la aduana no tendrá ningún tipo de intervención ${ }^{58}$. De igual modo, se establece que las ventas realizadas por catalanoaragoneses o sicilianos a mercaderes tunecinos, por mediación de trujamanes, que cuenten con avales y que hayan sido vistas y comprobadas por los compradores, no podrán ser anuladas, teniendo la aduana la potestad de obligar al pago previamente acordado. Idéntica normativa en lo que se refiere a las compras protagonizadas por oficiales reales: siempre que exista un contrato, la compra se considerará firme ${ }^{59}$.

El establecimiento detallado de estas medidas evidencia, con seguridad, los altos niveles de trasgresión y fraude que debían producirse. Los impagos de mercancías adquiridas por oficiales reales, incluso por los sultanes, aparecen con excesiva frecuencia en las reclamaciones elevadas por los operadores ante los funcionarios reales. Las cortes magrebíes son uno de los principales clientes y consumidores de las importaciones procedentes del continente europeo. No obstante, dichas operaciones podían constituir un negocio expuesto al llevar aparejado el riesgo de importantes pérdidas ante la posibilidad del impago de las deudas contraídas por los sultanes ${ }^{60}$.

El acuerdo describe con detalle las medidas a adoptar en el caso de que se produzca el impago de las deudas. Una cuestión que concentra numerosos aspectos de fricción en las relaciones entre ambas comunidades. Uno de los puntos más conflictivos era el de los procuradores, no siempre reconocidos por los deudores magrebíes. El tratado precisa la obligatoriedad de presentar las actas de nombramiento de procuradores escritas en latín para posteriormente, en Túnez, ser traducidas al árabe ${ }^{61}$. Sólo una vez reconocida la autoridad de los procuradores, podrán éstos reclamar las cantidades adeudadas. Las cartas de deudas de la corte o de oficiales del rey podrán ser

58 "XXXI - Ítem, que totes les mercaderies e tota altre cosa que catalans o sicilians o altres sotsmeses dels senyors reys d'Aragó e de Sicília vendran per mans de torsimanys o corradors ab testimonis, que aytal venda sia e ésser dege sots fermansa de la duana de totes les tẹrres e senyoria del dit rey de Tunis; e les coses qui seran venudes sens torsimany, corrador o testimonis que la duana no sia en res tenguda.

XXXII - Item, que si alcun català o sicilià o sotsmès dels dits senyors reys d'Aragó e de Sicília vendrà alcunes mercaderies per mà de torsimany e haurà haüda arres o caparra, e aquell que les vol comprar les haurà vistes, que aytal venda pas e no puxa tornar atràs, e la duana sia tenguda fer pendre la mercaderia e fer pagar al català o sicilià per lo comprador lo preu de la dita mercaderia" [Pregón Mallorca, 6.09.1403].

59 “XXXIII - Ítem, que si alcun català o sicilià o sotsmès dels dits senyors reys d'Aragó e de Sicília comprarà alcunes mercaderies o coses d'alcun official del senyor rey de Tunis o d'altre terra que sia de la sua senyoria, e haurà en la sua mà carta testimonial de la dita sua compra, que aytal venda no puxa tornar atràs per lo dit official ne per altre successor d'equell, mas aytal venda sia ferma" [Pregón Mallorca, 6.09.1403].

${ }^{60}$ M.D. LóPEZ, La Corona de Aragón y el Magreb, pp. 131-132.

${ }^{61}$ "XXXXIII - Ítem, que la cort e la duana e les altres singulars persones del dit rey de Tunis degen pagar tot quan deuran als sotsmesos dels dits senyors reys d'Aragó e de Sicília als procuradors d'equells catalans o sicilians, mostrant emperò les lurs procures públiques en lạtí, no contrestant que en latí sien scrites e no en sarreynesch, e que les dites procures sien transladades de latí en morisch e que sien servades entre los sarreyns a poder demanar los dits deutes" [Pregón Mallorca, 6.09.1403]. 
legalmente cedidas entre mercaderes, eso sí, sólo entre catalanoaragoneses y sicilianos ${ }^{62}$.

En relación a los trujamanes, se detalla el sueldo o emolumento que deberán recibir por sus servicios. Aquél queda cifrado en un porcentaje sobre el valor de las mercancías objeto de transacción: 5 millareses de plata por cada 100 besantes. Es de suponer que los abusos debían ser una constante y con esta disposición se pretendía acabar con las diferencias, en ocasiones enormes, que podían resultar de la contratación de estos intérpretes ${ }^{63}$. La especificación que tots els torsimays sien e ésser degen aguals en lur office de torsimany e no sia entre aquells alcuna diferència ne propietat no deja lugar a dudas. Marineros, 'bastaixos' - mozos de cuerda-, correos, y otros, percibirán sus sueldos axí com antigament era acustumat per qualsevol averies (gastos ocasionales o imprevistos).

Los capítulos reiteran disposiciones ya habituales en otros tratados, entre ellas la referente a que catalanes y sicilianos podrán disponer de escribanos en todas las aduanas bajo jurisdicción del sultán hafsí y con el albarán obtenido podrán circular con absoluta libertad de movimientos, junto con sus mercancías, por cualquier territorio bajo jurisdicción tunecina ${ }^{64}$. Se les autoriza a comprar trigo, harina y demás víveres que quedarán exentos de tasa, siempre que sean para consumo de la tripulación de los navíos.

No es menos importante, el interés que desarrolla el texto en proteger a la colonia frente a las actuaciones indebidas de algunos de sus miembros. Por ello, los daños causados por operadores individuales no deberán repercutir

62 “XXXIII - Ítem, que si alcun català o sicilià o sotsmès dels dits senyors reys d'Aragó e de Sicília comprarà alcunes mercaderies o coses d'alcun official del senyor rey de ter Tunis o d'altre aytal venda no puxa tornar atràs per lo dit official ne per altre successor d'equell, mas aytal venda

XXXX ferma. . Îtem, que los dits catalans e sicilians pusquen fer cessió de las cartes dels deutes que deuen haver o rebre de la cort o dels officials del dit rey de Tunis, los uns als altres, catalans o sicilians ten solament" [Pregón Mallorca, 6.09.1403].

63“XXXIIII - Ítem, que tots els torsimanys siẹn e ésser degen aguals en lur offici de torsimany. e no sia entre aquells alcuna diferència ne proprietat; e sia pagat als dits torsimanys per lur salari

XXXXII - Item, que los catalans e sicilians e altres sotsmesos dels dits senyors reys d'A. a. é e de Sicília no sien tenguts de pagar per salaris de torsimanys ne de corradors sinó de millarases nous per cascun ròtol de seda acustumats dar al gran torsimany" [Pregón Mallorca, 6.09.1403].

${ }^{64}$ "XXXV - Ítem que.ls catalans o sicilians dels dits senyors reys hagen e haver degen en la duana de Tunis e en totes les altres terres del dit rey de Tunis scriva qui fassa los comptes e lurs rahons tota vagada que.s vullen; e pusquen los dits çatalans e sicilians fer lur compte e haüt albarà o pòlissa de lur spetxament anar on se volran, axí per mar com per terra, sens alcun empetxament; e si aprés per ventura los dits catalans o sicilians tornaran en les terras o lochs d'on seran partits, no.ls puxa ésser feta questió ne demanda de la primera rahó per alcuna occasió o causa. XXXVI - Item, que tots los catalans e sicilians sens alcun contrast puxen anar les hores acustumades en les naus, navilis e galeas per lurs necessitats segons que és acustumat; e que no.ls sia vedạt d'anạr e tornar en les viles e tẹrras del dit rey de Tunis; ne pusca ésser vedat ne feta alcuna inhibició de comprar forment, farina e altres vitưalles.per los patrons e mariners dẹls dits navilis, galleres e naus sensa pagar alcun dret de las dites vitualles; e si alcun català o sicilià o altre qui per català o sicilià serà reputat o s'espetxarà, dịà̀ $\mathrm{o}$ farà alcun mal o dan als sarreyns 0 a alcuna persona que per assò los altres catalans o sicilians no sien molestats, empetxats o detenguts en béns ne en persona, en axí que lo pare no sia detengut per lo fill ne lo fill per lo pare, ne un per altre no puxa ésser molestat ne agreujat per la dita rahó" [Pregón Mallorca, 6.09.1403]. 
en ningún caso en la situación del colectivo, ni en sus personas ni en sus bienes, circunstancias, por otro lado, que solían darse con relativa asiduidad.

Determinados capítulos refuerzan el principio que encabeza el tratado respecto a la seguridad de personas y bienes ${ }^{65}$. Especificaciones, como la libertad de desembarco en la Goleta y en cualquier otro puerto o playa tunecino, y la salvaguarda en caso de coincidencia con embarcaciones tunecinas, confirman el interés de ambas partes por asegurar la presencia de operadores europeos en general, en los mercados de Túnez. De forma que incluso se otorga la seguridad a embarcaciones de cristianos, con mención concreta de los castellanos, siempre que lleven cargamentos o pasaje catalanoaragonés o siciliano.

Una de las cuestiones más interesantes que es objeto de regulación corresponde a la posibilidad del fletamento de naves por parte del soberano tunecino o sus altos funcionarios. El texto contempla que pueda ser fletada una tercera parte de la totalidad de los barcos anclados en el puerto de Túnez, exceptuando aquellas naves que ya estuvieran cargadas o se encontrasen en proceso de carga, y haciéndose cargo la aduana de los costes de los fletes ${ }^{66}$. La contratación por parte del estado, que es la que aparece aquí descrita, se complementa con las negociaciones llevadas a cabo por particulares musulmanes que precisan de la intervención de naves cristianas para mantener los contactos con puertos europeos o magrebíes ${ }^{67}$.

Lanas, 'boldrons', 'anyines' - lana de corderos - cueros y “otras mercancías" se detallan como productos cuya compra es permitida en la

65 “XXXVII - Ítem, que si s'esdevendrà que la cort de la reyal magestat del rey de Tunis atorga a alcun cristià per qualsevol manera que les barques o navilis d'equell vinguen a la Goleta o strò a la duana de tunis, que sẹmblant gracia o licència dege atorgar als dits catalans e sicilians.

XXXVIII - Item, que si s'esdevendrà que alcun navili de qualsevol condició, sia galera o nau de catalans o de sicilians, per fortuna de temps vendrà o farirà en alcun loch o terra de la senyoria del dit rey de Tunis, per alcunes necessitats los dits catalans o sicilians pusquen legudament descarragar sens alcuna contradicció les robes e mercaderies lurs, e aqui puxen estar e habitar salvament e segura en béns e en persones sots fe e speransa e salvaguarda del dit rey de Tunis en totes les sues terres, e si de las mercaderies que hauran descarragades o hauran lensades de mar en terra volran carragar en los dits navilis, naus o galeres a les quals tal fortuna serà esdavenguda $\mathrm{o}$ en altres navilis, que assò pusquen fer e no sien tenguts pagar alcun dret.

XXXVIIII - Item, que si alcun cristià serà o navagară en alcuna nau, galera o altre navili d'alcun castellà, e aquell cristià, hage o no hage pau ab lo dit rey de Tunis, que aquell cristià sia tractat e haüt per la reyal magestat del dit rey de Tunis axí com català o siciliâ, exceptat aquellas persones que personalment haguessen fet dan a alcun sarreyn sotsmès del dit rey de Tunis.

XXXX - Item, que si alcun navili, galera o nau d'alcun català o sicilià serà en mar o en port alcun de la senyoria del dit rey de Tunis, e alcun navili, nau o galera de sarreyns sotsmesos a la senyoria del dit rey semblantment serà en los dits ports o mar, que los dits navilis de catalans e de sicilians sien salves e sagurs dels dits sarreyns en béns e en persona" [Pregón Mallorca, 6.09.1403].

66“XXXXI - Ítem, si alcun mọhat o la alta magestạt del rey de Tunis per alcunes sues necessitats volrà noliejar alcuns navilis de catalans o de sicilians qui seran en to port de Tunis, que la dita reyal magestat pusca noliejar la tersa part de tots los navilis qui seran atrobats en lo dit port e en aquells carragar totes aquellas coses que.s volrà e portar-les on li plaurà; emperò que del nòlit sia en concòrdia ab los patrons de dits navilis, lo qual nòlit, pus que sie en concòrdia, hage pagar la duana, emperò que no pusque haver ne noliejar alcun navili qui sia ja carragat o hage comensat a carragar; e la dita duana sia tenguda pagar tot lo nòlit jassia los dits navilis no sien carragats de tot" [Pregón Mallorca, 6.09.1403]. Similares disposiciones aparecen en otros tratados. Véanse algunos ejemplos en M. D. LóPEZ, La Corona de Aragón y el Magreb, p. 384, nota 150 .

${ }^{67}$ M.D. López, La Corona de Aragón y el Magreb, pp. 384-389. 
alhóndiga y que luego podrán ser trasladados a los almacenes y tiendas axí com antigament fer solien. Antes de ser embarcadas para su traslado a Europa, dichas mercancías deberán ser revisadas por un testigo enviado expresamente por la aduana, tras lo cual los embalajes serán sellados sin que puedan ser exigibles nuevas inspecciones ${ }^{68}$.

Las últimas disposiciones hacen mención expresa al ejercicio de actividades corsarias ${ }^{69}$. Se prohíbe el embarque de catalanoaragoneses y sicilianos en navíos armados en corso contra tunecinos, y se les exige su denuncia y entrega en la aduana de Túnez en caso de poder apresarlos. Es más, si el sultán de Túnez decidiera armar navíos para darles caza, estos mercaderes deberían prestarle ayuda y consejo, llegando incluso a guiar las embarcaciones para facilitar su apresamiento. De igual modo, el rey de Túnez se compromete a prestar ayuda a los mercaderes víctimas de estas expediciones, al tiempo que les reconoce su seguridad y salvaguarda, tanto en tierra como en mar.

Por último, los dos capítulos finales concretan la aplicación de la salvaguarda. Se detalla la extensión de aquélla a personas de cualquier nacionalidad que desembarquen en puertos tunecinos en compañía de

68"XXXXIIII - Ítem, que sia leguda cosa als dits catalans e sicilians demunt dits comprar lanes, boldrons, anyines, cuyrs e altres mercaderies de qualsevol alarbs e sarrenys dins l'alfôndech en lo qual les dites robes e mercaderies e altres se solen vendre, e aquellas mercaderies fer portar a lurs matzens o botiges axí com antigament fer solien; e que los dits catalans e sicilians de las mercaderies que seran per ells venudes no sien tenguts dar o fer tara a ull, mas lo sach o allò on serà tal mercaderia sia pasat al pes e sia dat per tara; e com alcun dels dits catalans o sicilians se volrà partir de Tunis o d'alcun loch sotsmès al dit rey de Tunis, la duana sia tengut trametre un testimoni en lo alfòndech del catalans o sicilians, e aquell testimoni dege veure la caxa, scurmas o boneta dels dits mercaders, e vists les dites caxa, scurmas o boneta, que la dege,fer ligar e carragar e que altre vagada no sia vista ne regonaguda.

XXXXV-Item, que los dits catalans o sicilians no sien tenguts ne degen pagar per lur roba 0 mercaderies als bastaxos, mariners, correus, infants de la duana, ne a altres semblants, sinó axí com antigament era acustumat per qualsevol averies" [Pregón Mallorca, 6.09.1403].

69"XXXXVIII - Ítem, que alcuns catalans o sicilians demunt dits no gosen o presumesquen navagar ab alcuns navilis de corsaris qui fassen cors contra la reyal magestat de Tunis ne de sos sotsmesos, mas tots los sarreyns sotsmesos a la dita reyal magestat sien sauls e sagurs en béns e en persones en totes, les terres e lochs de la senyoria dels dits reys d'Aragó e de Sicília.

XXXXVIIII - Item, que si alcun català $o$ sicilià $o$ altre qui sia del destret lur, armarà alcun navili o galea per anar o fer cors contra los sotsmeses del dit rey de Tunis, los catalans e sicilians sien tenguts fer lur poder en pendre los dits corsaris en persona e en béns e, si.ls poden haver, fassen đequells justícia axí com de corsaris semblants se deu fer, e los béns d'equells dar a la duana del dit rey de Tunis; e si aquells corsaris no poden haver en persona, que los béns d'equells qui haver se poran, sien denunciats a la dita duana; e si per ventura la reyal magestat de Tunis o aquells en assò diputats volien armar alcuns navilis per pendre e haver los dits corsaris, lavores los dits catalans o sicilians sien tenguts donar en asso consell, favor e ajuda, e si.s convendrà que vagen ab ells per pendre a haver lọs dits corsaris e malfectors.

L - Item, si alcun català $o$ sicilià armara alcuna galea 0 altre navili per anar en cors, e alcun sarreyn exira de Tunis o de qualsevol loch del rey de Tunis, que los dits catalans e sicilians sien tenguts e degen aquells gordar e defendre si en lurs mans vendran axí en béns com en persona; e semblantment, si los sarreyns seran en cors contra alcunes gents e los catalans o sicilians seran o partiran de Tunis o d'altres lochs de la senyoria d'equell, sia tenguda la reyal magestat de Tunis e la duana aquell o aquells catalans o sicilians, si en mans vénen dels dits corsaris, fer sạlvus e sagurs en béns e en persona, en terra e en mar; e si per ventura los catalans o sicilians havien ops ajuda, que la dita reyal magestat de Tunis sia tenguda fer la dita ajuda" [Pregón Mallorca, 6.09.1403]. 
catalanoaragoneses y sicilianos ${ }^{70}$. Una vez garantizada la seguridad de las personas, se especifica que aquéllas estarán, eso sí, obligadas a abonar los tributos que por su nacionalidad les correspondan, aunque puntualiza que catalanoaragoneses y sicilianos pagan menos en la aduana que otros mercaderes.

Por otra parte, el tratado especifica de forma directa el pago fiscal que será de aplicación a uno de los productos textiles más significativo, como es el caso de la lana ${ }^{71}$. Destinada a alimentar las industrias textiles catalanoaragonesas o bien a la reexportación hacia otros centros de producción extranjeros, sobre todo italianos, la lana constituye uno de los productos preferentes en los cargamentos exportados desde las áreas magrebíes. Sin embargo, la documentación notarial analizada hasta el momento, siempre parcial, parece destacar como mercados de venta y puertos de salida de las producciones laneras del interior magrebí los enclaves de Honein y Alcudia, situados respetivamente en territorio zayyaní y mariní ${ }^{72}$.

La disposición, sin duda especial y concreta del tratado de 1403, podría venir a confirmar el interés de los operadores catalanoaragoneses en la lana producida en territorio tunecino e incluir a Túnez en la trilogía de puertos de exportación preferente de esta mercancía. Esta apreciación resulta aún más significativa si consideramos que es en el territorio hafsí donde se establece una férrea competencia entre operadores italianos y catalanoaragoneses. Los primeros, especialmente genoveses y pisanos, habían ido progresivamente, desde finales del XIII, principios del XIV, abandonando posiciones en las áreas más occidentales y centrales del Magreb para concentrar sus inversiones en Ifriqiya.

La lana constituía uno de sus principales objetivos. De escasa calidad, pero de precio asequible, llega a los talleres italianos directamente reexportada desde Mallorca, cuyo mercado estaba bien abastecido gracias al control, casi monopolístico, ejercido por sus operadores en los principales puertos del Magreb central ${ }^{73}$ o bien por compra directa en los enclaves tunecinos. Las ventajas fiscales concedidas en el tratado de 1403 colocan a los operadores catalanoaragoneses y sicilianos en una situación claramente aventajada y que, con toda probabilidad, debió reflejarse, mientras duró el acuerdo, en un aumento de las exportaciones laneras hacia la Corona de Aragón.

Los detallados capítulos nada mencionan del histórico tributo. El fortalecimiento y la unificación del sultanato hacían inviables las antiguas

70"LI - Ítem, que si alcuna persona que no sia català o sicilià navegarà ab los dits catalans o sicilians en les terres del dit rey de Tunis, que aytal persona sia tractada e honrada per los sotsmesos del dit rey axí pròpriament com son tractats e honrats los dits catalans e sicilians, exceptat emperò que aytal persona qui no sia català o sicilià pach e sia tengut de pagar los drets que acustumen pagar aquells qui són de la sua generació" [Pregón Mallorca, 6.09.1403].

71 "LII - Ítem, que los dits catalans o sicilians sien scusats e degen meyns pagar a la duana que altres persones per cascun quintar de lana deu millareses" [Pregón Mallorca, 6.09.1403].

${ }^{72}$ M.D. LóPeZ, La Corona de Aragón y el Magreb, pp. 548-556.

${ }^{73} \mathrm{M}$. Dolores LóPEZ, Las asociaciones de fletadores mallorquines bajomedievales: ¿un intento de monopolización del comercio magrebí?, "Anuario de Estudios Medievales", 24 (1994), $89-104$. 
reclamaciones del 'trahut'. El corso, el comercio y los cautivos vuelven a ser los protagonistas indiscutibles de las negociaciones. Retomamos el espíritu original de los tratados.

La tregua finalizó en 1408. A pesar de los intentos de reanudar las conversaciones, la muerte en 1409 de Martín el Joven de Sicilia, y poco después, en 1410, de su padre Martín el Humano, impidió que se llegara a materializar un nuevo tratado con el reino hafsí.

\section{CONCLUSIONES}

El tratado de 1403 constituye un punto de inflexión en las relaciones entre la Corona de Aragón y Túnez y refleja el cambio de estrategia de la corte catalanoaragonesa respecto al territorio hafsí. Desde finales del XIII, el principal punto de debate de las embajadas enviadas a la corte hafsí residía, fundamentalmente, en la cuestión de la deuda tributaria. Las peticiones se fundamentaban en la adquisición, que tras la ocupación de Sicilia por Pedro el Grande, se había producido de los derechos sobre los tributos adeudados por el reino de Túnez a los soberanos sicilianos. Un análisis de los acuerdos conservados revela que el logro de dichos objetivos siempre estará en relación directa al grado de inestabilidad del poder del sultán que ocupa el trono en el momento en que se negocia la tregua y, por tanto, de su mayor o menor predisposición a aceptar las condiciones económicas impuestas por los representantes del monarca catalanoaragonés.

A partir de 1360 importantes cambios en la coyuntura política del reino de Túnez influyeron decisivamente en el desarrollo de los contactos diplomáticos. Ese mismo año se suscribe un tratado con Túnez y Bugía con una duración de diez años. Las cláusulas incluyen idénticas especificaciones a las registradas en tratados anteriores referentes a cuestiones de regulación de piratería, infraestructura comercial e impuestos de exportación-importación de mercancías. No obstante, la principal novedad del tratado es la suscripción del reconocimiento del pago de un tributo anual por parte del sultán hafsí al monarca catalanoaragonés, enmascarado, eso sí, bajo la apariencia de una devolución de impuestos de aduanas.

¿Por qué acepta el sultán este acuerdo oneroso? El sultán firmante, Abu Isaac, gobernaba un territorio libre del peligro mariní, pero enormemente desmembrado en su interior. El reconocimiento del tributo implicaba una posición de privilegio frente a sus oponentes en caso de necesitar una ayuda militar, naval o terrestre, y le aseguraba, teóricamente, una cierta cobertura ante la retomada política expansionista de los mariníes, quienes habían vuelto a ocupar Tremecén y hacían temer la continuidad de las expediciones hacia el este. Sin embargo, las reiteradas embajadas enviadas por el Ceremonioso, siempre con el objeto de recaudar el prometido tributo, muestran en la práctica las reticencias de Abu Isaac a cumplir las obligaciones adquiridas y señalan que el compromiso de sufragar el tributo quedaba en papel mojado. Por otro lado, el tratado, al ser personal tampoco incluía la totalidad del 
territorio hafsí, dejando fuera algunos de los puertos más importantes donde negociaban los operadores de la Corona de Aragón.

La situación se habría de complicar a partir de 1370. Abu-l-Abbas, el emir de Constantina y Bugía, consigue ocupar ocupar las ciudades de Bona, Bugía, Tedelis y Túnez e instaurarse como única cabeza visible de un estado hafsí reunificado. A partir de estos momentos se abre una nueva etapa en las relaciones Corona de Aragón-Ifriqiya, caracterizada por un cambio en la política de Pedro el Ceremonioso. La negociación se transforma en hostilidad, provocada, eso sí, por una política exterior agresiva potenciada por el sultán hafsí y reflejada en un incremento de las actividades piráticas desarrolladas desde los puertos de Bona y Bugía. La reacción ante la continuada violencia de los hafsíes son las dos cruzadas valenciano-mallorquinas contra Tedelis y Bona de 1398-99. Esta coyuntura política supeditará la orientación de las futuras negociaciones.

El tratado concluido en 1403 entre Abu Faris y Martín el Humano y que incluía a Sicilia, es un claro exponente de las nuevas preocupaciones e intereses del soberano catalanoaragonés. Un número importante de capítulos, los primeros, se dedicaron a regular el problema de la redención de cautivos y las condiciones en que ésta debía llevarse a cabo, seguramente el aspecto más importante en aquella coyuntura para el monarca, mientras que otros incluían ordenaciones sobre el corso.

Y de nuevo los aspectos de índole comercial hacen su aparición: la salvaguarda de los mercaderes, la edificación de una nueva alhóndiga para los comerciantes de la Corona de Aragón, el traspaso de la antigua a los sicilianos, el nombramiento de cónsules diferenciados, la reglamentación de impuestos, los sueldos de trujamanes, escribanos, correos, la igualdad de derechos con el resto de comerciantes europeos,... De estos capítulos no se desprende nada nuevo. Estamos ante disposiciones relativamente corrientes, incluidas, eso sí, cuestiones algunas de índole más específica.

Nada se dice sobre las viejas reclamaciones de carácter tributario, pero resulta interesante comprobar que se ha logrado concretar una política fiscal diferencial para catalanoaragoneses y sicilianos respecto a operadores de otras nacionalidades. Parecen intuirse ventajas fiscales que se concretan en un producto específico, la lana. De esta forma la colonia catalanoaragonesa quedaba en una situación de privilegio frente a sus más directos competidores, los operadores italianos, especialmente los genoveses.

El tratado tuvo sólo una vigencia de cinco años. La muerte de Martín el Joven y de Martín el Humano, y la crisis política derivada de los problemas sucesorios, imposibilitaron la renovación de la tregua. ¿Cómo afectó esta situación a la colonia catalanoaragonesa? Sólo podemos hacer conjeturas y establecer paralelismos con situaciones anteriores. La inexistencia de una tregua no implica, en ningún caso, el cese de los intercambios comerciales: los intereses económicos prevalecen siempre sobre las coyunturas políticas. No obstante, es probable que esas privilegiadas condiciones fiscales fuesen derogadas, devolviendo a los mercaderes catalanoaragoneses a la situación anterior a 1403. Nuestro desconocimiento sobre el desarrollo de los contactos 
llevados a cabo a lo largo del cuatrocientos nos impide resolver por el momento el verdadero alcance en el tiempo de aquellas medidas.

Fecha de recepción del artículo: junio de 2010.

Fecha de aceptación y versión final: septiembre de 2010. 